\title{
sciendo
}

\author{
Current Issues in Pharmacy and Medical Sciences \\ Formerly ANNALES UNIVERSITATIS MARIAE CURIE-SKLODOWSKA, SECTIO DDD, PHARMACIA \\ journal homepage: http://www.curipms.umlub.pl/
}

\section{Metabolism study of morpholinium 2- ((4- (2-methoxyphenyl)- 5-(pyridin-4-yl) -4H-1,2,4-triazole-3-yl)thio) acetate}

\author{
BORYS VARYNSKYI ${ }^{*}$, ANDRIY KAPLAUSHENKo
}

State Medical University, Pharmaceutical Faculty, Zaporozhye, Ukraine

\begin{tabular}{|c|c|}
\hline ARTICLE INFO & ABSTRACT \\
\hline $\begin{array}{l}\text { Received } 01 \text { June } 2019 \\
\text { Accepted } 02 \text { August } 2019\end{array}$ & $\begin{array}{l}\text { Aim. The purpose of this study is to reveal the determination of the structure of the } \\
\text { main metabolite of morpholinium 2-(4-(2-methoxyphenyl)-5-(pyridin- } 4-y l)-4 H \text { - }\end{array}$ \\
\hline $\begin{array}{l}\text { Keywords: } \\
\text { 1,2,4-triazole, } \\
\text { metabolism, } \\
\text { liquid chromatography, } \\
\text { mass spectrometry. }\end{array}$ & $\begin{array}{l}\text { 1,2,4-triazole-3-yl)thio)acetate (an active pharmaceutical ingredient - API) by } \\
\text { way of chromatography through mass spectrometry detection, utilizing the liquid } \\
\text { chromatography system Agilent } 1260 \text { Infinity and mass spectrometry detector (single } \\
\text { quadrupole detector Agilent } 6120) \text {. In the work, the graph of the change in the area } \\
\text { of the peak of the metabolite from time after the introduction of the API solution } \\
\text { was constructed. Moreover, the charges on the atoms of } 2 \text {-((4-(2-methoxyphenyl)-5- } \\
\text { (pyridin-4-yl)- } 4 H-1,2,4 \text {-triazol-3-yl)thio) acetate were calculated and the structure of } \\
\text { the methyl derivative was proposed. We saw that the methylation of the active substance } \\
\text { during metabolism formed a 5-((carboxymethyl)thio)-4-(2-methoxyphenyl)-1-methyl- } \\
\text { 3-(pyridin-4-yl)- } 4 H-1,2,4 \text {-triazol-1-um cation through N-methyltransferase. }\end{array}$ \\
\hline
\end{tabular}

\section{INTRODUCTION}

Derivatives of 1,2,4-triazole exhibit various forms of biological activity. Among these are Morpholinium 2-((4-(2-methoxyphenyl)-5-(pyridin-4-yl)-4H-1,2,4-triazol-3-yl)thio)acetate (an active pharmaceutical ingredient - API). This demonstrates neuroprotective activity with adaptogenic properties of the antioxidant and anti-ischemic mechanisms of action [1]. The study of this metabolite has potential benefits.

Methods of determination of API and impurities in bulk drugs by the application of HPLC were described in the works [2-3]. Furthermore, an API-forced degradation was discussed in the article [4], and the development of the HPLC method for application with another 1,2,4-triazole derivative was presented by the authors in [5].

The ubiquity and quantitative content of many substances in the body can be determined by the presence of characteristic metabolites. This is important in chemical-toxicological studies, doping control, therapeutic drug monitoring, and others. In addition, there are many examples wherein a drug's metabolites exhibit greater pharmacological activity than the starting material, for example, ambroxol, an active metabolite of bromhexine (bromhexine VIII) [6]. Therefore, the determination of metabolites in order to further test their activity allows the creation of new, more effective

\footnotetext{
* Corresponding author

e-mail: varinsky@zsmu.zp.ua
}

medicines. In addition, more toxic substances can be formed during metabolism. Thus, investigation of biotransformation patterns allows creating more effective and less toxic medicinal substances.

There are various ways of assessing the metabolism of xenobiotics in humans and animals $[7,8]$. The most known and convenient for metabolism research is the method of liquid chromatography with mass spectrometry detection [7]. An attempt to determine the API metabolite structure by the GC MS was described in the work [9]. In addition, the metabolism of triazole derivatives was studied earlier. For example, voriconazole and three main metabolites were quantified by high-performance liquid chromatography coupled to mass spectrometry [10]. Therein, the authors studied N-oxide and hydroxy metabolites.

The purpose of this study is to determine the structure of the main metabolite of morpholinium 2-(4-(2methoxyphenyl)-5-(pyridin-4-yl)-4H-1,2,4-triasole-3-yl) thio)acetate by applying liquid chromatography with mass spectrometry detection.

\section{MATERIALS AND METHODS}

\section{Equipment}

Liquid chromatography system Agilent 1260 Infinity, mass spectrometry detector (single quadrupole Agilent $6120)$. 


\section{LC conditions}

The utilized column was a Agilent Zorbax RX-SIL $(4.6 \times 50 \mathrm{~mm}, 1.8 \mu \mathrm{m})$. Herein, the eluent consisted of $0.1 \%$ $\mathrm{HCOOH}$ in acetonitrile and $100 \mathrm{mM} \mathrm{HCOONH}_{4}$ in water (80:20). Moreover, the isocratic modewas $0.4 \mathrm{~mL} / \mathrm{min}$, and the injection volume was $1 \mathrm{uL}$.

\section{Mass Spectrometry detection conditions}

The drying gas (nitrogen) flow rate was $121 / \mathrm{min}$, and the drying gas temperature was $347^{\circ} \mathrm{C}$, while the nebulizer pressure was $35 \mathrm{psig}$, and the fragmentor voltage was $150 \mathrm{~V}$. The $\mathrm{m} / \mathrm{z}$ scan range was $100-1000$.

\section{Reagents}

Morpholinium 2-((4-(2-methoxyphenyl)-5-(pyridin-4yl)-4H-1,2,4-triazol-3-yl)thio)acetate was synthesized at the Department of Physical and Colloidal Chemistry of Zaporozhye State Medical University. Its structure was confirmed by Professor Kapaushenko A.G. [11].

Highly purified water $\left(18 \mathrm{M} \Omega\right.$ at $\left.25^{\circ} \mathrm{C}\right)$ was prepared by Direct Q 3UV (Merk Millipore). The acetonitrile "HPLC Super Gradient" was supplied by Avantor Performance Materials Poland S.A., Poland, and the Methanoic acid "For analysis" 98\% was manufactured by AppliChem GmbH, Germany.

\section{RESULTS AND DISCUSSION}

Determination of the structure of the main metabolite by liquid chromatography via mass spectrometry detection

In this work, we studied the metabolism of the API by means of applying liquid chromatography with mass
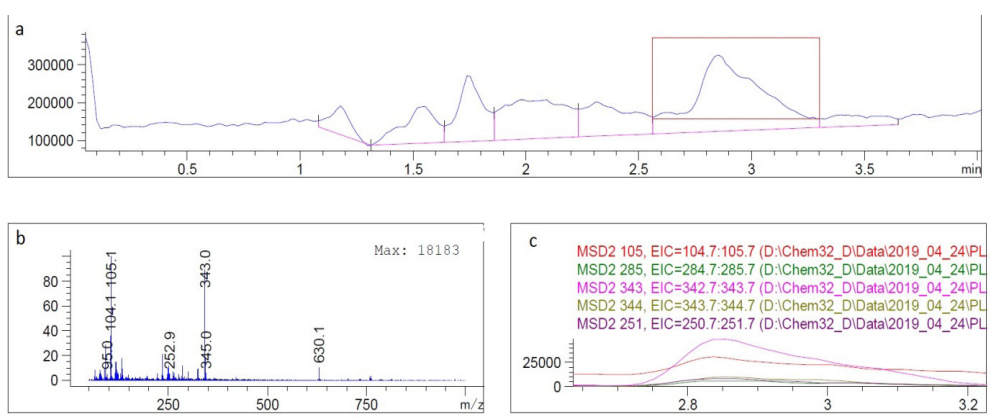

Figure 1. (a) TIC chromatogram of API metabolism products. (b) Mass spectrum of peak with retention time $2.855 \mathrm{~min}$ at $200 \mathrm{~V}$ fragmentor voltage. (c) EIC chromatogram
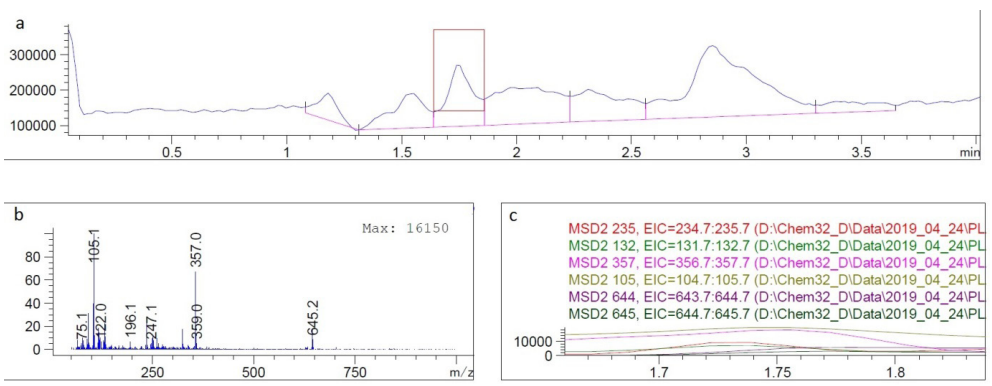

Figure 2. (a) TIC chromatogram of API metabolism products. (b) Mass spectrum of peak with retention time $1.753 \mathrm{~min}$ at $200 \mathrm{~V}$ fragmentor voltage. (c) EIC chromatogram spectrometry detection. Therein, the peak that corresponds to the API was found to be at 2.855 min (Figure 1), while the quasimolecular ion was seen at $\mathrm{m} / \mathrm{z} 343$ (Figure 1).

The peak of the main metabolite was found at retention time 1,753 min (Figure 2). The basic quasimolecular ion was at $\mathrm{m} / \mathrm{z} 357$. Therein, the monoisotopic mass 357 is equal to the sum of the monoisotopic mass of the quasimoingredient (343) and 14 amu $(343+14=357)$.

Traditionally, this can be explained as being the product of the methylation of 2-((4-(2-methoxyphenyl)-5-(pyridin-4yl)-4H-1,2,4-triazol-3-yl)thio)acetic acid with the formation of 5-((carboxymethyl)thio)-4-(2-methoxyphenyl)-1-methyl3-(pyridin-4-yl)-4H-1,2,4-triazol-1-ium cation as metabolite at mass 357 (The handbook [8] states within Table 17.1 on page 312 that in the formation of the metabolite, when 14 amu is added on, this indicates the mean methylation of an active substance) (Figure 3).

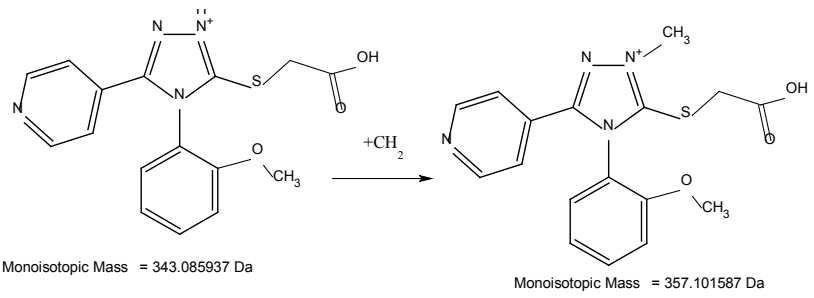

Figure 3. Methylation of the 5-[(carboxymethyl)sulfanyl $]-4-(2-$ methoxyphenyl)-3-(pyridin-4-yl)-4H-1,2,4-triazol-1-ium ion

\section{New interpretation of the gas chromatography electron ionization mass spectra for the main mabolite structure determination}

Previously, in [9], the authors studied the metabolism of this API using gas chromatography and mass spectrometry detection. They considered that the product of metabolism is the corresponding thione. As a result of new experimentation, we give a new interpretation of the mass spectrum (Fig. 4).

The molecular ion with $\mathrm{m} / \mathrm{z} 356$ corresponds to the methyl-substituted metabolite (Fig. 4). Subsequently, the ion with $\mathrm{m} / \mathrm{z} 341$ is formed due to cleavage of $-\mathrm{CH}_{3}$, and through further cleavage of $-\mathrm{OH}$, the acylium cation with $\mathrm{m} / \mathrm{z}$ 325 appears. The acylium cation is resolute due to resonance stabilization and it is formed from the carboxylic acids and their derivatives (aliphatic and aromatic) [12-14]. Furthermore, the acylium cation for short aliphatic acids is more stable than the molecular ion that we observe via mass spectrum analysis. Thus, the studied molecule is the short aliphatic acid. When splitting $-\mathrm{CH}_{3}$ from the methoxygroup, a cation with $\mathrm{m} / \mathrm{z} 311$ is formed. Since tetramethylchlorosilane was used for derivatization in the gas chromatography study, then a tetramethylsilyl cation with $\mathrm{m} / \mathrm{z} 73$ appeared in the mass spectrum.

This result corresponds to the experiments carried out using liquid chromatography with mass spectrometry detection. 


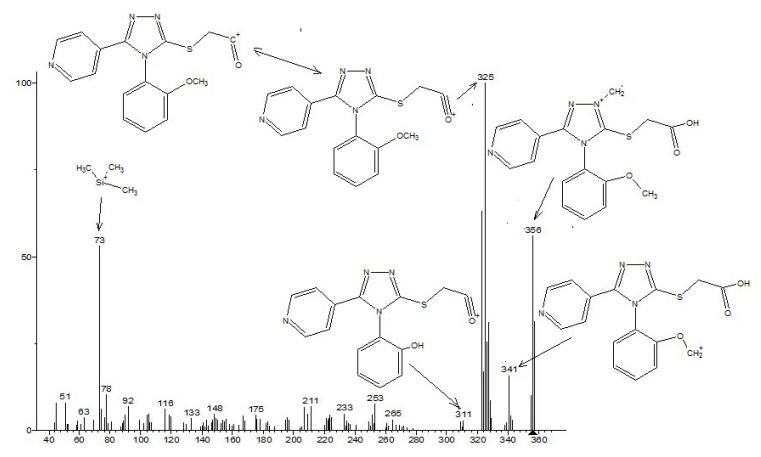

Figure 4. Mass spectrometry fragmentation. Mass spectrum of electron ionization

\section{Mechanism of formation of the main metabolite}

According to [8], the methyl group is transferred to a nucleophilic acceptor substrate that contains atoms with an excess of electron density, such as oxygen, nitrogen or sulfur. However, methylation on O (oxygen) usually occurs for phenols or catechols, on S (sulfur) for the sulfhydryl groups, on $\mathrm{N}$ (nitrogen) for aliphatic, aromatic and N-heterocyclic compounds $[8,15,16]$. The test compound is, thus, not phenol or catechol, it has no sulfhydryl group, but it makes reference to N-heterocyclic compounds. Therefore, the molecule was methylated by means of N-methyltransferase. The enzyme N-methyltransferase is an enzyme of the second phase of the metabolism of some xenobiotics. It also transforms endogenous substances such as serotonin [8].

Methylation occurs on the atom having the highest electron density. In our study, calculations were made utilizing ChemOffice by applying the Hückel method. The result of this work, through ChemOffice numbering, reveals that the most negative charge had a nitrogen atom in the $\mathrm{N}(4)$ position (Table 1, Figure 5). Thus, an N-1-methyl derivative was formed (Figure 3 ). The proposed metabolism pattern makes it possible to screen for other 1,2,4-triazole compounds.

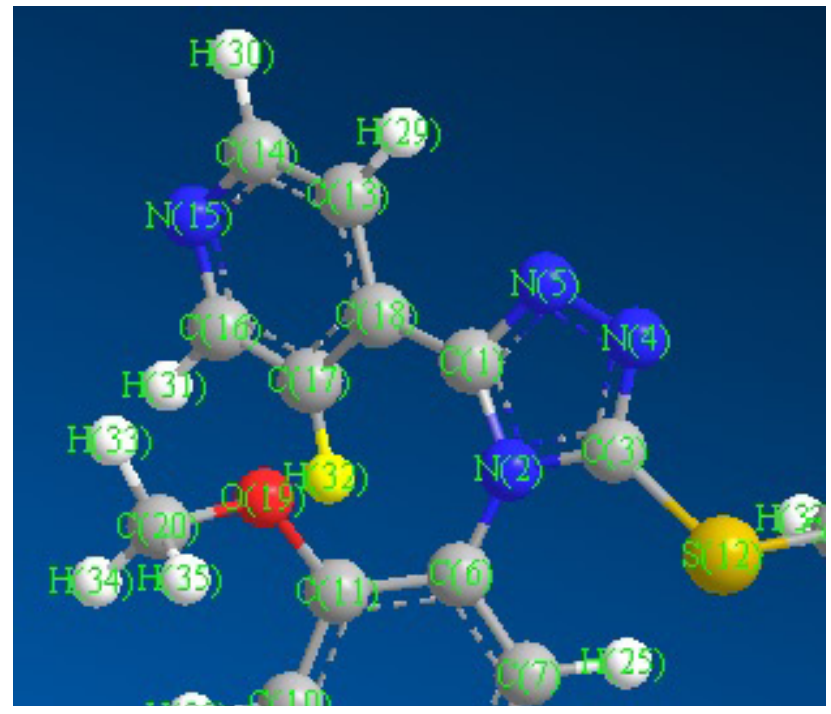

Figure 5. Numbering of atoms by the ChemOffice
Table 1. Charge on atoms calculated according to Hückel's method

\begin{tabular}{|c|c|}
\hline Atom & Charge \\
\hline$C(1)$ & 0.0963014 \\
\hline$N(2)$ & 0.538035 \\
\hline$C(3)$ & 0.134131 \\
\hline $\mathrm{N}(4)$ & -0.319124 \\
\hline$N(5)$ & -0.298193 \\
\hline$c(6)$ & 0.108039 \\
\hline$C(7)$ & -0.112527 \\
\hline$C(8)$ & -0.0822295 \\
\hline$C(9)$ & -0.0770588 \\
\hline$C(10)$ & -0.123938 \\
\hline$C(11)$ & 0.208192 \\
\hline $\mathrm{S}(12)$ & 0.0839514 \\
\hline$C(13)$ & -0.127292 \\
\hline$C(14)$ & 0.114743 \\
\hline$N(15)$ & -0.238815 \\
\hline$C(16)$ & 0.11503 \\
\hline$C(17)$ & -0.12208 \\
\hline$C(18)$ & 0.080811 \\
\hline$O(19)$ & -0.218597 \\
\hline$C(20)$ & 0.0746731 \\
\hline$C(21)$ & -0.122282 \\
\hline$C(22)$ & 0.607658 \\
\hline $\mathrm{O}(23)$ & -0.642595 \\
\hline $\mathrm{O}(24)$ & -0.193182 \\
\hline
\end{tabular}

The dynamics of the change in the area of the metabolite versus time is shown in Figure 6.

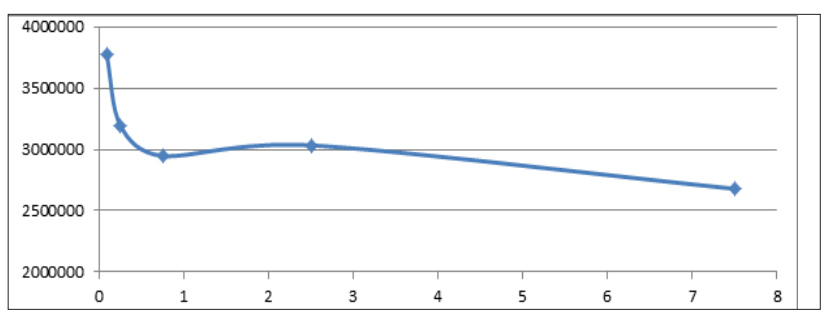

Figure 6. Change in methylated metabolite content over time. The dependence of the peak area from time 0

The maximal concentration of metabolite was observed at 5 minutes. In 7.5 hours, the content of the metabolite decreases by about $30 \%$.

\section{CONCLUSIONS}

1. A study of the morpholin metabolism of 2-((4-(2methoxyphenyl) -5- (pyridin-4-yl) -4H-1,2,4-triazol-3-yl) thio) acetate was undertaken.

2 . The methylation of the active substance during metabolism formed a 5-((carboxymethyl)thio)-4-(2methoxyphenyl)-1-methyl-3-(pyridin-4-yl)-4H-1,2,4triazol-1-ium cation. The methylation is stimulated by N-methyltransferase. 
3. The charges on the atoms of 2 - ((4- (2-methoxyphenyl) -5- (pyridin-4-yl) -4H-1,2,4-triazol-3-yl) thio) acetate were calculated and the structure of the methyl derivative was proposed.

4. The proposed metabolism pattern makes it possible to screen for other 1,2,4-triazole compounds.

5. A graph of the change in the area of the peak of the metabolite from time after the introduction of the API solution was constructed.

\section{CONFLICT OF INTERESTS}

There is no conflict of interest.

\section{AKNOWLEDGMENTS}

Authors acknowledge the assistance of rector of Zaporozhye State Medical University, Professor Yu. M. Kolesnyk in making it possible to utilize the lab equipment of the laboratory of liquid chromatography and mass-spectrometry.

\section{ORCID iDs}

Borys Varynskyi (Dhttps://orcid.org/0000-0002-1551-8879

\section{REFERENCES}

1. Kaplaushenko AG. Research to create a new original national drug on the basis of 1,2,4-triazoles. Scientific Journal of the Ministry of Health of Ukraine. 2013;2:115-21.

2. Varynskyi BO, Kaplaushenko AG. The development and validation of HPLC-DMD method for intermediate products impurities determination of morpholinium 2-((4-(2-methoxyphenyl)-5(pyridine-4-yl)-4H-1,2,4-triazole-3-yl)thio) acetate in bulk drug. Zaporozhye Med J. 2017;3:373-80.

3. Varynskyi B, Kaplaushenko A, Al Zidan F. Development And Validation of HPLC-DAD Method Of Determination Morpholin-4ium 2-((4-(2-methoxyphenyl)-5-(pyridin-4-yl)-4H-1,2,4-triazol-3-yl) thio) acetate In A Bulk Drug. RJPBCS. 2018;9(5):2200-9.
4. Varynskyi B, Kaplaushenko A. The Force Degradation Study of the Morpholinium 2-((4-(2-Methoxyphenyl)-5-(Pyridin-4-YL)-4H-1,2,4Triazol-3-YL) Thio) Acetate. Indones J Pharm. 2019;30(1):25-34.

5. Shcherbyna R, Parchenko V; Varynskyi B; Kaplaushenko A. The development of HPLC-DAD method for determination of active pharmaceutical ingredient in the potassium 2-((4-amino-5(morpholinomethyl)-4H-1,2,4-triazol-3-yl)thio)acetate substance. Curr Issues Pharmy Med Sci. 2019;1:5-9.

6. https://www.drugbank.ca/drugs/DB06742

7. Rousu T. Liquid chromatography-mass spectrometry in drug metabolism studies. Oulu: University of Oulu, 2012:17-20.

8. A handbook of bioanalysis and drug metabolism. Edited by Gary Evans. Boca Raton London New York Washington: CRC PRESS, 2004:223-258, 259, 312.

9. Parchenko VV, Kaplaushenko AG, Panasenko OI, Knysh YeG. Determination of possible metabolites of some $\mathrm{S}$-derivatives 1,2,4-triazoles. Ukr Biopharm J. 2010;5(10):32-7.

10. Scholz I, Oberwittler H, Riedel Kl-D, Burhenne J, Weiss J, Haefeli WE, Mikus G. Pharmacokinetics, metabolism and bioavailability of the triazole antifungal agent voriconazole in relation to CYP2C19 genotype. BJCP. 2009;68(6):906-15.

11. Kaplaushenko AG. Synthesis, structure and biological activity of 4-mono- and 4,5-derivatives 1,2,4-triazoles-3-thione. Doctor of PharmSci thesis. Zaporozhye: Zaporozhye State Medical University; 2012.

12. Lebedev AT. Mass-spectrometry in organic chemistry. Moskow: Binom, Laboratory of knowledges; 2003:258.

13. Benoit F, Holmes JL. The mass spectra of carboxyltc acids-I: fragmentation mechanisms in maleic and fumaric acids and related compounds. OMS. 1969;2:591-601.

14. Holmes JL, Benoit F. The mass spectra of carboxylic acids-III: the structures of molecular and fragment ions in benzoic acid and related molecules. OMS. 1970;4:97-107. https:/doi.org/10.1002/ oms.1210040111

15. Ansher SS, Jakoby WB. Amine N-methyltransferases from rabbit liver. J Biol Chem. 1986;261(9):3996-4001.

16. Crooks PA, Godin CS, Damani LA, Ansher SS, Jakoby WB. Formation of quaternary amines by $\mathrm{N}$-methylation of azaheterocycles with homogeneous amine N-methyltransferases. Biochem Pharmacol. 1988;37(9):1673-7. 